\title{
Genetic redundancy masks diverse functions of the tumor suppressor gene PTEN during C. elegans development
}

\section{Yo Suzuki and Min Han ${ }^{1}$ \\ Howard Hughes Medical Institute and Department of Molecular, Cellular, and Developmental Biology, University of Colorado, Boulder, Colorado 80309, USA}

Genetic redundancy is associated with a large percentage of genes. We investigated PTEN (phosphatase and tensin homolog deleted on chromosome 10) tumor suppressor gene functions that eluded single mutant analyses, using a Caenorhabditis elegans genome-wide screen. We show that at least 27 genes collaborate with the worm PTEN homolog daf-18 for various functions previously concealed by genetic redundancy, including embryogenesis, cuticle turnover, egg laying, and oocyte maturation. In one example, daf-18 appears to constitute a cell-autonomous germline signal that converges with a somatic gonad signal mediated by ceh-18 at a kinase inhibition. We provide evidence that $\mathrm{daf}-18$ elicits some functions independent of the downstream gene daf-16.

Supplemental material is available at http://genesdev.org.

Received September 23, 2005; revised version accepted

December 22, 2005.

PTEN (phosphatase and tensin homolog deleted on chromosome 10) is a major tumor suppressor gene, controlling various processes such as cell cycle progression, cell survival, translation, and metabolism (Sulis and Parsons 2003). PTEN encodes a phosphatase that catalyzes the dephosphorylation of phophatydylinositol-3, 4, 5-trisphosphate $\left(\mathrm{PIP}_{3}\right)$, thereby antagonizing the role of phosphoinositide-3 (PI-3) kinase and Akt kinase/protein kinase B (Maehama and Dixon 1998; Sulis and Parsons 2003).

There is a single PTEN homolog $($ daf-18) in Caenorhabditis elegans. Loss-of-function (lf) mutations in daf-18 block entry into the diapause (dauer) stage and reduce life span by affecting the daf-2 (insulin receptor)/ age-1 (PI-3 kinase) pathway (Ogg and Ruvkun 1998). Unlike fly dPTEN(lf) mutants and mouse PTEN(lf) mutants, which are lethal as embryos (Sulis and Parsons 2003), the vast majority of C. elegans daf-18(lf) mutants complete normal development (Gil et al. 1999). We hypothesize that daf-18 plays important roles in multiple aspects of $C$. elegans growth and development, yet many of the effects of daf-18(lf) mutations are masked by genetic redundancy mainly due to functions of genes that

[Keywords: Synthetic screen; daf-18; daf-16; ceh-18; PI-3 kinase] ${ }^{1}$ Corresponding author.

E-MAIL mhan@colorado.edu; FAX (303) 735-0175.

Article and publication are at http://www.genesdev.org/cgi/doi/10.1101/ gad.1378906. are not structurally related to $d a f-18$. The viability of the C. elegans mutants should facilitate screening for genes that collaborate with PTEN. Previously, we and others have taken advantage of a similar characteristic for the C. elegans Rb gene (lin-35) (Lu and Horvitz 1998; Fay et al. 2002).

\section{Results and Discussion}

\section{daf-18 is expressed in the germline}

We first examined the daf-18 expression patterns using in situ hybridization. daf-18 message was present predominantly in the germline in larvae and adults $193 \%$, $n=88$ ) (Supplementary Fig. S1). This is a specific signal not detected in the daf-18 deletion mutant $(n=89)$ or in glp-4(bn2) animals $(n=112)$, where little germline proliferation occurs (Beanan and Strome 1992). The technique employed is not suitable for detecting daf-18 expression in the embryos. A daf-18 reporter gene was expressed in various cells including neurons in the nerve ring, gut cells, and embryonic cells (Masse et al. 2005; data not shown), although the prominent germline expression was not detected using this approach. These expression patterns suggest that $d a f-18$ has a role in the germline or embryos, in addition to the known role in dauer and life span regulation. Sterility (Ste) or embryonic lethality (Emb) may thus be a phenotype resulting from simultaneous inactivation of $d a f-18$ and a functionally redundant gene.

RNA interference (RNAi) screen reveals essential functions of daf-18 in C. elegans development

To identify genes that function redundantly with daf-18, we screened a $C$. elegans whole-genome RNAi library. RNAi is effective for knocking down genes in the germline and for uncovering maternal-effect phenotypes, and is therefore expected to be suitable for examining genes that function with daf-18. In this screen, we fed synchronized, starved L1 animals with Escherichia coli generating double-stranded RNA (dsRNA) for C. elegans genes (Materials and Methods). Among the 16,757 genes represented in the library, we found 27 genes that, when inactivated, cause a strong Ste or Emb phenotype in a daf18-null mutant (Table 1). RNAi of two genes caused Emb, and RNAi of 25 genes caused Ste phenotypes in the daf-18(lf) mutant. Among the Ste genes, nine also caused a low level of Emb RNAi phenotypes, suggesting that these genes interact with daf-18 in multiple stages of development.

In all cases tested, a daf-18(rf) (reduction-of-function) allele (Ogg and Ruvkun 1998) also had synthetic phenotypes (Table 1). In addition, another RNAi-sensitive strain eri-1(lf) (Kennedy et al. 2004) behaved similarly to the daf-16(+); daf-18(+) control strains. To confirm that the phenotypes we detected were the results of specific gene inactivation and not any deleterious effects of RNAi, we generated double mutants for several genes for which a mutation is available. mec-8(lf) mutations caused a maternal-effect, synthetic Emb phenotype (Table 2; see below), whereas unc-73(rf) and goa-1(lf) mu- 
Table 1. Genes that, when inactivated in a daf-18-null mutant, cause a strong synthetic phenotype

\begin{tabular}{|c|c|c|c|c|}
\hline \multirow{2}{*}{$\begin{array}{l}\text { Gene name } \\
\text { (chromosome location) }\end{array}$} & \multirow[b]{2}{*}{ Protein encoded } & \multicolumn{3}{|c|}{ Brood size as an indication of sterility \pm SD } \\
\hline & & $\operatorname{daf} 18(+)[$ eri-1 $(l f)]$ & daf-18(lf) $[$ daf-18(rf)] & daf-16(lf) \\
\hline \multicolumn{5}{|l|}{ [Actin cytoskeleton] } \\
\hline unc-73 (I) & Guanine nucleotide exchange factor & $99 \pm 16$ & $5 \pm 1$ & $117 \pm 4$ \\
\hline$s m a-1(\mathrm{~V})$ & $\beta_{\mathrm{H}^{-}}$spectrin & $\begin{array}{l}143 \pm 33 \\
{[73 \pm 10]}\end{array}$ & $\begin{array}{l}9 \pm 1 \\
{[2 \pm 1]}\end{array}$ & $143 \pm 7$ \\
\hline $\mathrm{T} 25 \mathrm{~F} 10.6(\mathrm{~V})^{\mathrm{a}}$ & Calponin-like protein ${ }^{\mathrm{a}}$ & $96 \pm 19^{\mathrm{a}}$ & $6 \pm 4^{\mathrm{a}}$ & $30 \pm 18^{\mathrm{a}}$ \\
\hline \multicolumn{5}{|l|}{ [Extracellular matrix] } \\
\hline bli-5 (III) & Protease inhibitor & $\begin{array}{r}74 \pm 19 \\
{[56 \pm 6]}\end{array}$ & $\begin{array}{c}4 \pm 2 \\
{[1 \pm 1]}\end{array}$ & $50 \pm 4$ \\
\hline $\operatorname{col}-98(\mathrm{III})^{\mathrm{a}}$ & Cuticle collagen $^{\mathrm{a}}$ & $38 \pm 8^{\mathrm{a}}$ & $4 \pm 1^{\mathrm{a}}$ & $26 \pm 11^{\mathrm{a}}$ \\
\hline \multicolumn{5}{|l|}{ [G protein signaling] } \\
\hline $\operatorname{goa}-1(\mathrm{I})^{\mathrm{a}, \mathrm{b}}$ & Heterotrimeric $\mathrm{G}$ protein $\alpha$ subunit $\mathrm{Go}^{\mathrm{a}}$ & $76 \pm 23^{\mathrm{a}}$ & $2 \pm 1^{\mathrm{a}}$ & $19 \pm 6^{\mathrm{a}}$ \\
\hline str-30 (V) $)^{\mathrm{a}, \mathrm{b}}$ & Sevem TM receptor ${ }^{\mathrm{a}}$ & $94 \pm 27^{\mathrm{a}}$ & $6 \pm 5^{\mathrm{a}}$ & $38 \pm 8^{a}$ \\
\hline$s r w-96(\mathrm{~V})^{\mathrm{a}, \mathrm{b}}$ & Seven TM receptor ${ }^{\mathrm{a}}$ & $115 \pm 30^{\mathrm{a}}$ & $6 \pm 4^{a}$ & $26 \pm 8^{\mathrm{a}}$ \\
\hline \multicolumn{5}{|l|}{ [Transcription] } \\
\hline $\operatorname{egl}-27(\mathrm{II})^{\mathrm{a}, \mathrm{b}}$ & MTA1 of the NuRD complex ${ }^{a}$ & $69 \pm 8^{\mathrm{a}}$ & $1 \pm 1^{\mathrm{a}}$ & $8 \pm 3^{a}$ \\
\hline$d p y-28(\mathrm{III})^{\mathrm{b}}$ & Non-SMC condensin subunit & $145 \pm 24$ & $6 \pm 3$ & $150 \pm 16$ \\
\hline ceh-18 (X) & POU homeodomain protein & $\begin{array}{c}94 \pm 10 \\
{[62 \pm 18]}\end{array}$ & $\begin{array}{c}2 \pm 2 \\
{[1 \pm 1]}\end{array}$ & $125 \pm 38$ \\
\hline $\operatorname{sex}-1(\mathrm{X})^{\mathrm{b}}$ & Nuclear hormone receptor & $\begin{array}{l}68 \pm 10 \\
{[23 \pm 9]}\end{array}$ & $\begin{array}{l}1 \pm 1 \\
{[0 \pm 0]}\end{array}$ & $3 \pm 1^{\mathrm{a}}$ \\
\hline$t t x-3(X)^{\mathrm{a}}$ & LIM homeodomain protein ${ }^{\mathrm{a}}$ & $156 \pm 6^{\mathrm{a}}$ & $4 \pm 1^{\mathrm{a}}$ & $38 \pm 18^{\mathrm{a}}$ \\
\hline $\mathrm{D} 2021.1(\mathrm{X})^{\mathrm{a}, \mathrm{b}}$ & $\begin{array}{l}\text { Protein with tetratricopeptide repeats and } \\
\text { a jmjC domain }{ }^{a}\end{array}$ & $\begin{array}{r}34 \pm 8^{\mathrm{a}} \\
{[48 \pm 7]}\end{array}$ & $\begin{array}{l}2 \pm 2^{\mathrm{a}} \\
{[1 \pm 1]^{\mathrm{a}}}\end{array}$ & $11 \pm 2^{\mathrm{a}}$ \\
\hline \multicolumn{5}{|c|}{ 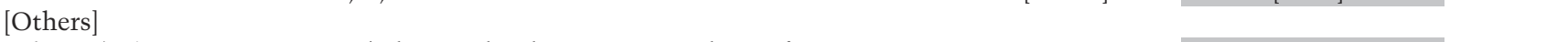 } \\
\hline$h r p-1$ (IV) & RNA/telomere-binding protein, splicing factor & $\begin{array}{l}109 \pm 22 \\
{[33 \pm 36]}\end{array}$ & $\begin{array}{c}0 \pm 0 \\
{[0 \pm 0]}\end{array}$ & $99 \pm 19$ \\
\hline $\mathrm{F} 25 \mathrm{H} 2.5$ (I) & NDP kinase & $63 \pm 8$ & $3 \pm 1$ & $92 \pm 17$ \\
\hline$n r f-6(\mathrm{II})^{\mathrm{a}, \mathrm{b}}$ & Acyltransferase $^{a}$ & $\begin{array}{l}64 \pm 10^{\mathrm{a}} \\
{[90 \pm 5]}\end{array}$ & $\begin{array}{c}4 \pm 3^{\mathrm{a}} \\
{[1 \pm 1]^{\mathrm{a}}}\end{array}$ & $15 \pm 7^{a}$ \\
\hline$v a b-19(\mathrm{II})^{\mathrm{a}}$ & Protein with ankyrin repeats ${ }^{a}$ & $\begin{array}{r}87 \pm 18^{\mathrm{a}} \\
{[88 \pm 19]}\end{array}$ & $\begin{array}{c}2 \pm 1^{\mathrm{a}} \\
{[1 \pm 1]^{\mathrm{a}}}\end{array}$ & $26 \pm 9^{a}$ \\
\hline Y48C3A.9 (II) ${ }^{\mathrm{a}}$ & $\begin{array}{l}\text { Single-stranded DNA-binding protein with a } \\
\text { lissencephaly type-1-like homology motif }\end{array}$ & $66 \pm 14^{\mathrm{a}}$ & $2 \pm 1^{\mathrm{a}}$ & $32 \pm 5^{\mathrm{a}}$ \\
\hline C53A3.2 (V) & Hydrolase & $183 \pm 3$ & $16 \pm 9$ & $230 \pm 32$ \\
\hline F48G7.9 (V) ${ }^{\mathrm{a}}$ & Phorbol esters/diacylglycerol-binding domain protein ${ }^{\mathrm{a}}$ & $115 \pm 11^{\mathrm{a}}$ & $3 \pm 1^{\mathrm{a}}$ & $67 \pm 7^{\mathrm{a}}$ \\
\hline Y113G7B.17 (V) & Protein arginine $\mathrm{N}$-methyltransferase ${ }^{\mathrm{a}}$ & $\begin{array}{l}33 \pm 8^{\mathrm{a}} \\
{[27 \pm 12]}\end{array}$ & $\begin{array}{c}1 \pm 1^{\mathrm{a}} \\
{[1 \pm 1]^{\mathrm{a}}}\end{array}$ & $26 \pm 5^{\mathrm{a}}$ \\
\hline $\mathrm{F} 54 \mathrm{D} 11.2(\mathrm{~V})^{\mathrm{a}, \mathrm{b}}$ & Novel protein ${ }^{\mathrm{a}}$ & $108 \pm 6^{\mathrm{a}}$ & $3 \pm 2^{\mathrm{a}}$ & $55 \pm 2^{\mathrm{a}}$ \\
\hline Y50D4B.7 (V) & Novel protein ${ }^{\mathrm{a}}$ & $\begin{array}{c}129 \pm 6^{\mathrm{a}} \\
{[115 \pm 13]}\end{array}$ & $\begin{array}{c}6 \pm 1^{\mathrm{a}} \\
{[6 \pm 4]^{\mathrm{a}}}\end{array}$ & $51 \pm 3^{a}$ \\
\hline Y51A2D.15 (V) & Novel protein ${ }^{\mathrm{a}}$ & $\begin{array}{r}80 \pm 11^{\mathrm{a}} \\
{[56 \pm 53]}\end{array}$ & $\begin{array}{c}2 \pm 1^{\mathrm{a}} \\
{[0 \pm 0]^{\mathrm{a}}}\end{array}$ & $19 \pm 7^{\mathrm{a}}$ \\
\hline Vector & NA & $\begin{array}{c}128 \pm 10 \\
{[119 \pm 20]}\end{array}$ & $\begin{array}{l}93 \pm 5 \\
{[45 \pm 10]}\end{array}$ & $201 \pm 14$ \\
\hline Vector $^{\mathrm{a}}$ & $\mathrm{NA}^{\mathrm{a}}$ & $75 \pm 7^{\mathrm{a}}$ & $\begin{array}{l}31 \pm 4^{\mathrm{a}} \\
{[35 \pm 12]^{\mathrm{a}}}\end{array}$ & $58 \pm 3^{\mathrm{a}}$ \\
\hline
\end{tabular}

\begin{tabular}{|c|c|c|c|c|}
\hline \multirow[b]{2}{*}{ Gene name } & \multirow[b]{2}{*}{ Protein encoded } & \multicolumn{3}{|c|}{ Embryonic lethal frequency ( $95 \%$ confidence interval) } \\
\hline & & daf $-18(+)$ & daf-18 (lf) & daf-16 (lf) \\
\hline $\operatorname{mec}-8(\mathrm{I})$ & RNA-binding protein, splicing factor & $\begin{array}{c}8 \% \\
(5-13 \%)\end{array}$ & $\begin{array}{c}73 \% \\
(62 \%-81 \%)\end{array}$ & $\begin{array}{c}32 \% \\
(27-38 \%)\end{array}$ \\
\hline$d a b-1$ (II) & $\begin{array}{l}\text { Adaptor protein, Drosophila-disabled } \\
\text { homolog }\end{array}$ & $\begin{array}{c}8 \% \\
(6-11 \%)\end{array}$ & $\begin{array}{c}78 \% \\
(69-85 \%)\end{array}$ & $\begin{array}{c}93 \% \\
(90-95 \%)\end{array}$ \\
\hline Vector & NA & $\begin{array}{c}4 \% \\
(2-8 \%)\end{array}$ & $\begin{array}{c}11 \% \\
(8-15 \%)\end{array}$ & $\begin{array}{c}0 \% \\
(0-1 \%)\end{array}$ \\
\hline
\end{tabular}

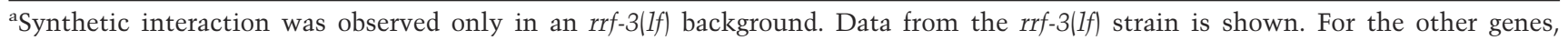
synthetic interaction was observed in both $r r f-3(I f)$ and non-rrf-3(If) backgrounds, and data from the non-rrf-3(If) strain is shown. (Highlighted) Data was statistically significant $(\alpha=0.05)$ compared with the daf-16(+); daf-18(+) control and with the vector control. ${ }^{b}$ RNAi also caused a low level of synthetic Emb phenotype in the daf-18(lf) mutant. 
Table 2. Interaction between mec- 8 and daf- 18 alleles

\begin{tabular}{lc}
\hline Genotype of the parents & Emb $\%(n) 20^{\circ} \mathrm{C}$ \\
\hline Wild type & $2 \%(346)$ \\
mec-8 (e398) & $1 \%(243)$ \\
daf-18 (nr2037) & $1 \%(137)$ \\
mec-8; daf-18 & $94 \%(119)$ \\
mec-8+; daf-18 & $13 \%(1094)$ \\
mec-8; daf-18/+ & $7 \%(907)$ \\
mec-8; daf-18 $\times$ mec-8 (males) & $2 \%(174)$ \\
mec-8; daf-18 $\times$ daf-18 (males) & $5 \%(105)$ \\
\hline
\end{tabular}

tations caused a synthetic Ste phenotype with the daf18(lf) mutation. The brood size of unc-73(rf); daf-18(lf) was 16 (10 parents examined), compared with 137 $[n=10$, unc-73(rf)], $222[n=19$, daf-18(lf)], or $261(n=10$, wild type), and the brood size of goa-1(lf); daf-18(lf) was $8(n=11)$, compared with $45[n=9$, goa-1(lf)]. Surprisingly, the brood size of daf-18(lf); ceh-18(lf) was 120 $(n=8)$, essentially identical to that of the single mutants $[120, n=8$, ceh-18(lf); see above]. However, when these animals were starved in the L1 stage as in the original screen, the brood sizes were $4[n=70$, daf-18(lf); ceh18(lf)], 70 [n=10, daf-18(lf)], and 125 [ $n=24$, ceh-18(lf)]. Therefore, genetic mutations reproduced the RNAi data, validating that our RNAi approach was effective.

\section{Identified genes interact with different branches of the daf-2 pathway}

To examine whether the identified genes function with the daf-2 pathway as a whole or with a branch including daf-18, we treated a daf-16-null mutant with RNAi of these genes. daf-16 encodes a FOXO transcription factor, acting downstream of this pathway (Lin et al. 1997; Ogg et al. 1997). We found that for 14 Ste genes, the phenotypic enhancement between RNAi and the daf-16(1f) mutation was statistically insignificant $(\alpha=0.05)$ when compared with the effect of RNAi on the daf-16(+) control strain or with the phenotype of the untreated daf16(lf) mutant (Table 1), consistent with the possibility that these genes interact with branches of the daf-2 pathway that diverge upstream of daf-16. In agreement with these RNAi results, the Emb phenotype of the mec-8(lf) daf-16(lf) mutant was $83 \%$ penetrant $(n=308)$, comparable to that of the mec-8(lf); daf-18(lf) mutant, whereas the brood size of the unc-73(1f) daf-16(lf) mutant, unlike the unc-73(lf); daf-18(lf) mutant, was high $(113, n=10)$, similar to that of the unc-73(lf) single mutant (see above). The daf-16(lf) single mutant was $0.4 \% \mathrm{Emb}$ $(n=500)$ and had the brood size of $199(n=9)$. In addition, mec-8(lf); akt-1(gf) (a gain-of-function mutation in a kinase gene that acts negatively on daf-16) was $34 \%$ Emb $(n=123)$, compared with $2 \%[n=259$; akt-1(gf)].

\section{daf-18 acts in parallel to ceh-18 in ovulation}

Among the 27 genes, four function with the actin cytoskeleton, three encode components in G-protein signal transduction pathways, two are related to the extracellular matrix, six affect transcription, and two encode splicing factors (Table 1). To investigate the synthetic phenotypes in detail, we focused on a few representative genes. ceh-18 encodes a POU-class, homeodomain-containing transcription factor that regulates gonadal sheath cell differentiation (McCarter et al. 1997; Rose et al. 1997). daf-18(lf); ceh-18(RNAi) animals, when starved as L1s, had a Ste phenotype at a frequency of $77 \%(n=44)$, compared with $10 \%[n=40$, daf-18(lf)], $0 \%[n=38$, ceh18(RNAi)], $13 \%$ [ $n=80$, ceh-18(lf)], or $0 \%$ ( $n=40$, wild type). The gonads were often skinny and defective in migration in these animals, but these were defects also observed in the daf-18(lf) mutant not treated with RNAi. In addition, DAPI staining showed normal nuclear morphologies in the gonadal arm (data not shown).

Under Nomarski optics, we observed in all daf-18(1f) animals treated with ceh-18 RNAi $(n=6)$, the first oocytes entered the spermatheca only halfway and clogged the ovary (Fig. 1A-C). The gonadal sheath contraction appeared to be too weak to complete ovulation. Later these gonads displayed a massively disorganized appearance probably due to the rupture or degradation of oocytes. Although the disorganized appearance was occasionally observed in the untreated daf-18(lf), the rate of the first oocytes entering the spermatheca was high in the daf-18(lf) (five out of five) or ceh-18(lf) (three out of three) mutant.

In the wild-type germline, oocytes arrest at the diakinesis stage of meiotic prophase I prior to fertilization. Defective ovulation in ceh-18(lf) mutants deregulates this arrest, causing oocytes to undergo multiple rounds of DNA replication without cytokinesis to generate endomitotic (Emo) nuclei (Iwasaki et al. 1996; McCarter et al. 1997; Rose et al. 1997). Consistent with the enhancement interaction between $d a f-18$ and ceh-18, we found that the daf-18(lf) mutant treated with ceh-18 RNAi had

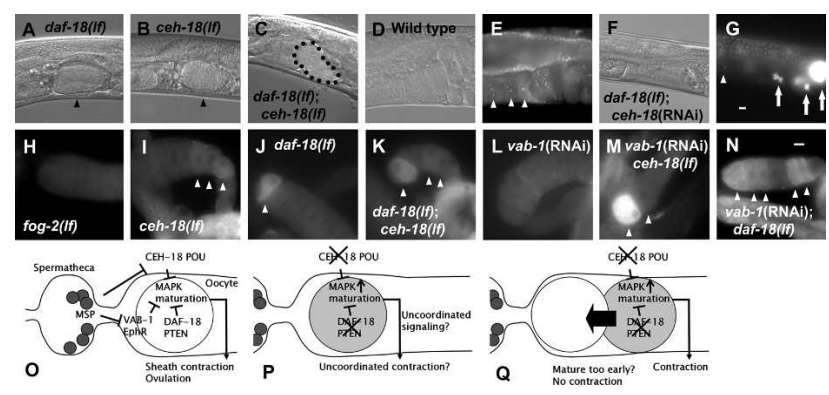

Figure 1. daf-18 interacts with $c e h-18$ to regulate oocyte maturation. $(A-C)$ Ovulation of the first oocyte in indicated strains. These animals were starved as L1s. The oocyte entered the spermatheca (arrowheads) in daf-18(lf) and ceh-18(lf) mutants, but failed to complete ovulation in daf-18(lf); ceh-18(lf) (dotted line). (D-G) Nomarski $(D, F)$ and DAPI staining $(E, G)$ images showing the Emo phenotype (arrows) of oocyte nuclei. Arrowheads indicate normal diakinesis nuclei. $(H-N)$ MAP kinase activation in oocytes of unmated females of indicated strains. These strains all contain fog-2(lf). Stained oocytes are indicated with arrowheads in $I, J, K, M$, and $N$. (O-Q) Models to explain how daf-18 and ceh-18 pathways converge on MAP kinase to affect ovulation. (O) VAB-1 and CEH-18 constitute a mechanism that activates MAP kinase in response to sperm. Maturing oocytes send a signal to the sheath to stimulate contraction for ovulation. DAF-18 plays a cell-autonomous role in this mechanism by inhibiting MAP kinase in the oocyte through the $\mathrm{PIP}_{3}: \mathrm{PIP}_{2}$ ratio or AKT kinases, but not DAF-16. $(P)$ When $d a f-18$ and ceh-18 are inactivated, MAP kinase activity is deregulated in an additive manner. This may lead to uncoordinated signaling by the oocyte or to uncoordinated response by the sheath to the intense signal if animals are starved as L1s. (Q) Alternatively, the oocyte may mature too early in this condition for correct signaling. Bar, $0.01 \mathrm{~mm}$ (bar in $G$ applies to $F, G$; bar in $N$ applies to the rest). 
a more penetrant Emo phenotype (84\%, 50 gonads examined) than untreated daf-18(lf) $(6 \%, n=36)$ or ceh-18null (19\%, $n=79)$ (Fig. 1D-G).

\section{daf-18 functions in the germline for the interaction with ceh-18}

Since laser ablation of the gonadal sheath cells, where ceh-18 functions, causes Emo at a higher frequency than a ceh-18(lf) mutation (McCarter et al. 1997; Rose et al. 1997), daf-18 and ceh-18 may function together in these cells. Alternatively, daf-18 may function in the germline where it is expressed. To determine the site of action for daf-18, we treated $r r f-1(1 f)$; ceh-18(lf) animals with daf18 RNAi. The $r r f-1(l f)$ mutation reduces the efficiency of RNAi in the soma (including the sheath cells), but not in the germline (Sijen et al. 2001). daf-18 RNAi caused a Ste phenotype at a similar frequency in both the ceh-18(lf) mutant $(72 \%, n=32)$ and the $r r f-1(1 f)$; ceh-18(lf) mutant $(73 \%, n=22)$, suggesting that daf-18 functions in the germline. The frequencies of Ste for the control strains were $0 \%[n=20, \operatorname{rrf}-1(l f)], 15 \%[n=20, \operatorname{rrf}-1(l f)$; ceh18(lf)], $0 \%[n=21, d a f-18($ RNAi) $]$, and $5 \%$ [ $n=20, r r f-$ 1(lf); daf-18(RNAi)].

\section{daf-18 and ceh-18 control mitogen-activated protein (MAP) kinase activation in oocyte maturation}

ceh-18 constitutes part of the sperm-sensing mechanism dependent on the gonadal sheath cells that inhibits oocyte maturation (Miller et al. 2003). We tested the possibility that the molecular target of this mechanism, MAP kinase, is also controlled by daf-18. In the presence of sperm, MAP kinase activation, as assessed using an antibody directed against the phosphorylated form of MAP kinase, is observed in the two to three most proximal oocytes (Miller et al. 2001; Page et al. 2001; data not shown). To eliminate the influence of sperm, we examined unmated females resulting from a fog-2(lf) mutation (Schedl and Kimble 1988). As previously reported (Miller et al. 2003), MAP kinase activation in oocytes was detected in a ceh-18(lf) mutant $144 \%$ gonad stained, average 0.8 oocyte stained per gonad, $n=110)$, whereas it was rarely observed in the fog-2(lf) control $(6 \%, 0.1, n=133)$ (Fig. 1H-K; Supplementary Table 1). We found that a daf-18(lf) mutant also had activated MAP kinase $145 \%$, $0.5, n=119$ ), suggesting that MAP kinase is the common target of $d a f-18$ and ceh-18. Consistent with the possibility that $d a f-18$ and ceh-18 act in parallel, the percentage of gonads stained $(60 \%)$ and the number of oocytes stained $(1.3, n=149)$ in a daf-18(lf); ceh-18(lf) double mutant were higher than in either single mutant. Starvation in the L1 stage did not further increase activated MAP kinase staining $(51 \%, 0.9, n=100)$, suggesting that the effect of starvation is mediated by a separate mechanism. It has been shown that the Eph receptor encoded by the $v a b-1$ gene functions as a receptor for major sperm protein (MSP) and also synergizes with ceh-18 (Miller et al. 2003). We examined the relationship between $v a b-1$ and $d a f-18$ by inactivating $v a b-1$ in nonstarved larvae using RNAi (Fig. 1L-N). vab-1 RNAi in ceh-18(lf) resulted in a dramatic increase in the intensity of staining (Fig. 1M); this was never observed with $v a b-1$ RNAi in the daf-18(1f) mutant, suggesting that daf-18 and ceh-18 function differently. These data are consistent with the possibility that $v a b-1$ and $d a f-18$ act in the same path- way. However, we noticed that multiple oocytes were stained at a higher frequency in $v a b-1$ (RNAi); daf-18(lf) $(24 \%, n=102)$ than in daf-18(lf) $(5 \%, n=119)$ or $v a b$ 1(RNAi) ( $2 \%, n=83)$ (Supplementary Table 1), leaving open the possibility that daf-18 constitutes a third pathway that modulates the activity of MAP kinase in the sperm-sensing mechanism. A signal from maturing oocyte has been known to stimulate the sheath contraction rate (McCarter et al. 1999). Based on these findings, we speculate that inactivation of $d a f-18$ and ceh-18 results in misregulation of MAP kinase in oocytes that affects this signaling event and, together with an unknown developmental defect caused by L1 starvation, leads to sterility (Fig. 1O-Q).

The mec-8; daf-18 double mutant has a maternal-effect Emb phenotype

mec- 8 is one of two genes that, when inactivated, caused $\mathrm{F}_{1}$ Emb, but not $\mathrm{P}_{0}$ Ste in the daf-18(1f) mutant. We found that Emb of the mec-8(lf); daf-18(lf) double mutant is a maternal-effect phenotype, observed only when parents are homozygous for both mutations (Table 2). Also, the Emb phenotype was rescued when a wild-type copy of mec- 8 or daf-18 was introduced from sperm (paternally rescuable). These results suggest that the activities of daf-18 and mec- 8 are provided both in the germline and in embryos, consistent with the expression patterns for daf-18. Previously mec-8(lf) mutants were shown to have a partially penetrant, cold-sensitive Emb phenotype (Lundquist and Herman 1994). The double mutant showed the same level of lethality at all temperatures tested (Supplementary Table 2). The mec-1(lf); daf-18(lf) double mutant did not have significant lethality $(2 \% \mathrm{Emb}, n=260)$, indicating that not all mec (mechanosensory-defective; WormBase) genes interact with daf -18 .

\section{daf-18 functions with mec-8 in embryonic elongation}

mec-8 (RNA-binding protein) controls the alternative splicing of unc-52, which encodes the integrin ligand perlecan (Rogalski et al. 1993; Lundquist et al. 1996; Spike et al. 2002). Among the arrested mec-8(RNAi); daf$18(1 f)$ embryos $(n=100), 72 \%$ arrested around the twofold stage similar to integrin pathway mutants (Rogalski et al. 1993; Williams and Waterston 1994), and the rest $(28 \%)$ assumed an exploded appearance similar to gex (gut on the exterior) mutants that are related to Rac GTPase functions (Fig. 2A-C). These embryos also had a lumpy appearance reminiscent of the phenotype of $h m p$ (humpback) mutants that are related to the cadherin complex (Piekny and Mains 2003). Therefore, mec8(RNAi); daf-18(lf) embryos have aspects of multiple elongation-defective phenotypes, possibly reflecting the sharing of components or the existence of cross-talk among different pathways. Consistent with the idea that the primary defect for lethality lies in the integrin pathway, the mec-8(RNAi); daf-18(lf) embryos had a defect in muscle organization as in integrin pathway mutants (Fig. $2 \mathrm{D}-\mathrm{F})$, and the frequency of this defect $(55 \%, n=20)$ was comparable to that of Emb $(63 \%, n=214)$ in these experiments. We carried out additional experiments to identify potential targets of this interaction without success (Supplemental Material). 


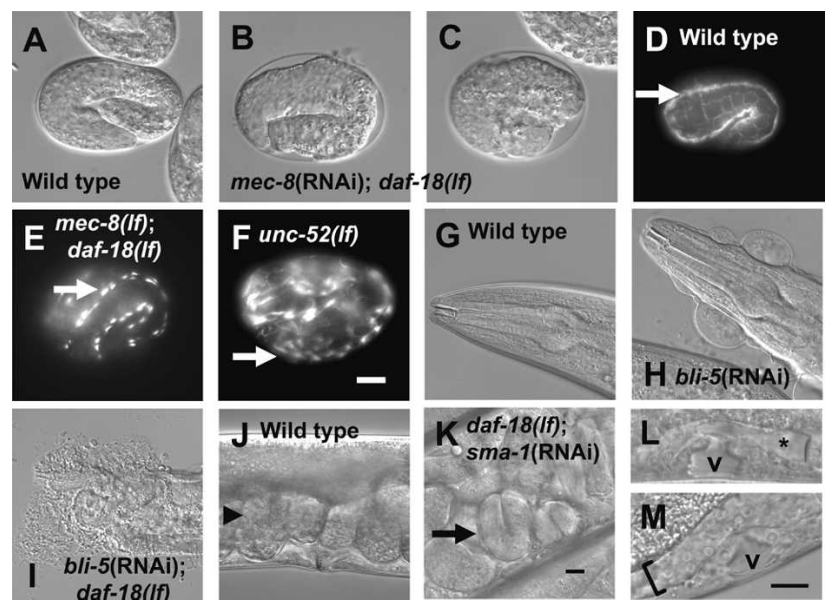

Figure 2. $(A-F)$ The mec-8(lf); daf-18(lf) embryos arrest in the twofold stage. $(A)$ Wild-type embryo reaching the threefold stage. $(B)$ mec-8(RNAi); daf-18(If) embryo that has arrested at the twofold stage. (C) mec-8(RNAi); daf-18(lf) embryo that has exploded (all examined $500 \mathrm{~min}$ after the first cleavage at $\left.25^{\circ} \mathrm{C}\right) \cdot(D-F)$ Myosin heavy chain A antibody staining showing muscle organization. Muscles (arrows) formed continuous bundles in wild type, but were fragmented in mec-8(lf); daf-18(lf) and unc-52(lf). The MH27 antibody that stains the apical junctions of epidermal cells (grid-like patterns) was included as a temporal marker. $(G-I)$ daf-18 interacts with bli-5. The head regions of indicated strains are shown. $(J-M)$ daf-18 interacts with sma-1. (J) Egg lining in wild type. Arrowhead points to a normal egg. (K) Egl phenotype of daf-18(lf); sma-1(RNAi). Arrow indicates a late-stage embryo. $(L, M)$ Developing uteri in L4stage larvae. The uterine lumen (asterisk) is adjacent to the vulva (v) in daf-18(lf) $(L)$, but is not found in a corresponding region (bracket) in daf-18(lf); sma-1(RNAi) (M). Bar, $0.01 \mathrm{~mm}$ (bar in $F$ applies to $A-F$; bar in $K$ applies to $G-K$; bar in $M$ applies to $L, M)$.

\section{daf-18 interacts with bli-5 to regulate cuticle turnover}

bli-5 encodes a protease inhibitor required for the integrity of the adult cuticle (WormBase). When daf-18(lf) mutants were treated with bli-5 RNAi, a striking phenotype was observed where animals exploded from the head region $160 \%, n=64$ vs. $0 \%$ in untreated animals, $n>100$ ) (Fig. 2G-I). bli-5 RNAi caused the blister (Bli) phenotype, where fluid accumulates between the cuticle and the epidermal cells (Fig. $2 \mathrm{H}$ ), but only rarely caused explosion in wild type $(0 \%, n=39)$ or $\operatorname{rrf}-3(1 f)(3 \%$, $n=74)$. Therefore, the $d a f-18(1 f)$ mutation enhances the cuticle defects of the bli-5 RNAi-treated animals. daf-18 may act upstream of genes encoding the matrix proteases targeted by BLI-5 or on the hormonal control of molting.

\section{daf-18 and sma-1 are required for egg laying}

sma-1 encodes a $\beta_{\mathrm{H}^{-}}$spectrin required for embryonic elongation (McKeown et al. 1998). RNAi of sma-1 on the daf-18(lf) strain caused an egg-laying-defective (Egl) phenotype (38\%, $n=198$ ) (Fig. 2J,K). This phenotype was infrequent in wild type treated with sma-1 RNAi $13 \%$, $n=149$ ), the rrf-3(lf) mutant treated with sma-1 RNAi $(13 \%, n=165)$, or a sma-1-null mutant $(13 \%, n=197)$. Therefore, the weak Egl phenotype caused by sma-1 inactivation is enhanced by the daf-18(lf) mutation. We found that the developing uterus was grossly abnormal in the L4 stage. In wild type, the uterine lumen and vulval invagination are separated by a thin membrane (Fig. 2L; Newman et al. 1996). In the daf-18(lf) mutant treated with sma-1 RNAi, the uterine lumen was sometimes fragmented $(35 \%, n=20)$ or nonexistent (10\%) (Fig. 3M). In other cases, the lumen contained cells that appeared to be undergoing necrosis $(40 \%)$. Overall, $84 \%(n=22)$ of the L4 stage vulva was not adjacent to the uterine opening, probably resulting in the accumulation of fertilized eggs in the uterus and the low brood size.

\section{Concluding remarks}

The processes protected by genetic redundancy are likely to be important to the cell and demand rigorous investigation. We show that the requirement for the PTEN homolog in animal survival and propagation is no different in C. elegans. The genetic redundancy we see in $C$. elegans for the developmental function of PTEN is also unlikely to be unique. For example, PTEN is expressed in mammalian skeletal muscles, where the PI-3 kinase pathway controls cell growth and differentiation, as well as glucose metabolism. However, the tissue-specific inactivation of PTEN in skeletal muscles does not result in any discernible phenotypes (Crackower et al. 2002). Some of the diverse functions we found in C. elegans for daf-18 are related to cell cycle regulation, extracellular matrix turnover, and assembly of the actin cytoskeleton. These are fundamental processes in development and are possibly related to PTEN functions in mammals.

We found that inactivation of daf-18 and ceh-18 results in MAP kinase activation in maturing oocytes. Interestingly, the PI-3 kinase pathway is also involved in oocyte maturation in mouse (Hoshino et al. 2004). Somatic gonadal sheath cells may be considered analogous to the mammalian follicle cells, which also inhibit oocyte maturation. Therefore, it is possible that the mechanisms of synthetic interactions involving PTEN are conserved at the molecular level, underscoring the significance of our findings in the C. elegans system.

\section{Materials and methods}

\section{C. elegans strains}

Information regarding the mutants used in this study is found in WormBase (http://www.wormbase.org). The detail is described in the Supplemental Material.

\section{In situ hybridization}

Starved L1 animals were grown for $\sim 48 \mathrm{~h}$ at $25^{\circ} \mathrm{C}$, the restrictive temperature for $g 1 p-4(b n 2 t s)$ (Beanan and Strome 1992), and were fixed and stained (Mochii et al. 1999). The probe was generated using sequences deleted in the nr2037 mutation (Gil et al. 1999).

\begin{abstract}
Starvation
Starved, synchronized L1s, free of contaminating bacteria, were used to obtain consistent RNAi results, except in $v a b-1$ experiments where fed L1s were used and rrf-1 experiments where progeny of animals starved as L1s were analyzed. To obtain starved L1 animals, eggs released from gravid hermaphrodites using a standard bleach treatment were cultured for $24 \mathrm{~h}$ at $16^{\circ} \mathrm{C}$ for the screen and for $18 \mathrm{~h}$ at $20^{\circ} \mathrm{C}$ for all the other tests. Starved daf-18(1f) L1s without bleach treatment were also Ste when treated with ceh-18 RNAi.
\end{abstract}

\section{RNAi screen}

RNAi screen was performed using a feeding library (Kamath et al. 2003). The detail for the screen process is described in the Supplemental Material.

Real-time quantitative PCR ( $q P C R$ )

Young gravid hermaphrodites were bleached to release embryos, which were harvested when the midpoint of development reached the embry- 
onic 1.5-fold stage. Standard protocols were used for RNA extraction, cDNA synthesis (poly-A-primed), and qPCR.

\section{Microscopy}

Embryos were fixed and stained using a hypochlorite method (Rogalski et al. 1993). Gonads were dissected out and stained as described (Miller et al. 2001). See Supplemental Material for details.

\section{Acknowledgments}

We thank C. Johnson for the daf-18(nr2037) allele; M. Fukuyama and J. Rothman for communicating unpublished results; J. Ahringer for the RNAi library; W. Wood, D. Fay, J. Schwarzbauer, K. Hirono, M. Ohmachi, R. Herman, M. Cui, J. Blanchette, M. Tucker, and D. Killian for advice; and CGC for strains. This project was funded by the HHMI, of which Y.S. was an associate and M.H. is an investigator.

\section{References}

Beanan, M.J. and Strome, S. 1992. Characterization of a germ-line proliferation mutation in C. elegans. Development 116: 755-766.

Crackower, M.A., Oudit, G.Y., Kozieradzki, I., Sarao, R., Sun, H., Sasaki, T., Hirsch, E., Suzuki, A., Shioi, T., Irie-Sasaki, J., et al. 2002. Regulation of myocardial contractility and cell size by distinct PI3KPTEN signaling pathways. Cell 110: 737-749.

Fay, D.S., Keenan, S., and Han, M. 2002. fzr-1 and lin-35/Rb function redundantly to control cell proliferation in C. elegans as revealed by a nonbiased synthetic screen. Genes \& Dev. 16: 503-517.

Gil, E.B., Malone Link, E., Liu, L.X., Johnson, C.D., and Lees, J.A. 1999. Regulation of the insulin-like developmental pathway of Caenorhabditis elegans by a homolog of the PTEN tumor suppressor gene. Proc. Nat1. Acad. Sci. 96: 2925-2930.

Hoshino, Y., Yokoo, M., Yoshida, N., Sasada, H., Matsumoto, H., and Sato, E. 2004. Phosphatidylinositol 3-kinase and Akt participate in the FSH-induced meiotic maturation of mouse oocytes. Mol. Reprod. Dev. 69: 77-86.

Iwasaki, K., McCarter, J., Francis, R., and Schedl, T. 1996. emo-1, a Caenorhabditis elegans Sec61p $\gamma$ homologue, is required for oocyte development and ovulation. J. Cell Biol. 134: 699-714.

Kamath, R.S., Fraser, A.G., Dong, Y., Poulin, G., Durbin, R., Gotta, M., Kanapin, A., Le Bot, N., Moreno, S., Sohrmann, M., et al. 2003. Systematic functional analysis of the Caenorhabditis elegans genome using RNAi. Nature 421: 231-237.

Kennedy, S., Wang, D., and Ruvkun, G. 2004. A conserved siRNA-degrading RNase negatively regulates RNA interference in C. elegans. Nature 427: 645-649.

Lin, K., Dorman, J.B., Rodan, A., and Kenyon, C. 1997. daf-16: An HNF3/forkhead family member that can function to double the life-span of Caenorhabditis elegans. Science 278: 1319-1322.

Lu, X. and Horvitz, H.R. 1998. 1in-35 and lin-53, two genes that antagonize a C. elegans Ras pathway, encode proteins similar to $\mathrm{Rb}$ and its binding protein RbAp48. Cell 95: 981-991.

Lundquist, E.A. and Herman, R.K. 1994. The mec-8 gene of Caenorhabditis elegans affects muscle and sensory neuron function and interacts with three other genes: unc-52, smu-1 and smu-2. Genetics 138: 83-101.

Lundquist, E.A., Herman, R.K., Rogalski, T.M., Mullen, G.P., Moerman, D.G., and Shaw, J.E. 1996. The mec-8 gene of C. elegans encodes a protein with two RNA recognition motifs and regulates alternative splicing of unc-52 transcripts. Development 122: 1601-1610.

Maehama, T. and Dixon, J.E. 1998. The tumor suppressor, PTEN/ MMAC1, dephosphorylates the lipid second messenger, phosphatidylinositol 3,4,5-trisphosphate. J. Biol. Chem. 273: 13375-13378.

Masse, I., Molin, L., Billaud, M., and Solari, F. 2005. Lifespan and dauer regulation by tissue-specific activities of Caenorhabditis elegans DAF-18. Dev. Biol. 286: 91-101.

McCarter, J., Bartlett, B., Dang, T., and Schedl, T. 1997. Soma-germ cell interactions in Caenorhabditis elegans: Multiple events of hermaphrodite germline development require the somatic sheath and spermathecal lineages. Dev. Biol. 181: 121-143.

1999. On the control of oocyte meiotic maturation and ovulation in Caenorhabditis elegans. Dev. Biol. 205: 111-128.
McKeown, C., Praitis, V., and Austin, J. 1998. sma-1 encodes a $\beta \mathrm{H}$-spectrin homolog required for Caenorhabditis elegans morphogenesis. Development 125: 2087-2098.

Miller, M.A., Nguyen, V.Q., Lee, M.H., Kosinski, M., Schedl, T., Caprioli, R.M., and Greenstein, D. 2001. A sperm cytoskeletal protein that signals oocyte meiotic maturation and ovulation. Science 291: 2144 2147.

Miller, M.A., Ruest, P.J., Kosinski, M., Hanks, S.K., and Greenstein, D. 2003. An Eph receptor sperm-sensing control mechanism for oocyte meiotic maturation in Caenorhabditis elegans. Genes \& Dev. 17: $187-200$.

Mochii, M., Yoshida, S., Morita, K., Kohara, Y., and Ueno, N. 1999. Identification of transforming growth factor- $\beta$-regulated genes in Caenorhabditis elegans by differential hybridization of arrayed cDNAs. Proc. Natl. Acad. Sci. 96: 15020-15025.

Newman, A.P., White, J.G., and Sternberg, P.W. 1996. Morphogenesis of the C. elegans hermaphrodite uterus. Development 122: 3617-3626.

Ogg, S. and Ruvkun, G. 1998. The C. elegans PTEN homolog, DAF-18, acts in the insulin receptor-like metabolic signaling pathway. Mol. Cell 2: 887-893.

Ogg, S., Paradis, S., Gottlieb, S., Patterson, G.I., Lee, L., Tissenbaum, H.A., and Ruvkun, G. 1997. The Fork head transcription factor DAF16 transduces insulin-like metabolic and longevity signals in C. elegans. Nature 389: 994-999.

Page, B.D., Guedes, S., Waring, D., and Priess, J.R. 2001. The C. elegans E2F- and DP-related proteins are required for embryonic asymmetry and negatively regulate Ras/MAPK signaling. Mol. Cell 7: 451-460.

Piekny, A.J. and Mains, P.E. 2003. Squeezing an egg into a worm: C. elegans embryonic morphogenesis. Scientific World Journal 3: 13701381.

Rogalski, T.M., Williams, B.D., Mullen, G.P., and Moerman, D.G. 1993. Products of the unc-52 gene in Caenorhabditis elegans are homologous to the core protein of the mammalian basement membrane heparan sulfate proteoglycan. Genes \& Dev. 7: 1471-1484.

Rose, K.L., Winfrey, V.P., Hoffman, L.H., Hall, D.H., Furuta, T., and Greenstein, D. 1997. The POU gene ceh-18 promotes gonadal sheath cell differentiation and function required for meiotic maturation and ovulation in Caenorhabditis elegans. Dev. Biol. 192: 59-77.

Schedl, T. and Kimble, J. 1988. fog-2, a germ-line-specific sex determination gene required for hermaphrodite spermatogenesis in Caenorhabditis elegans. Genetics 119: 43-61.

Sijen, T., Fleenor, J., Simmer, F., Thijssen, K.L., Parrish, S., Timmons, L., Plasterk, R.H., and Fire, A. 2001. On the role of RNA amplification in dsRNA-triggered gene silencing. Cell 107: 465-476.

Spike, C.A., Davies, A.G., Shaw, J.E., and Herman, R.K. 2002. MEC-8 regulates alternative splicing of unc-52 transcripts in C. elegans hypodermal cells. Development 129: 4999-5008.

Sulis, M.L. and Parsons, R. 2003. PTEN: From pathology to biology. Trends Cell. Biol. 13: 478-483.

Williams, B.D. and Waterston, R.H. 1994. Genes critical for muscle development and function in Caenorhabditis elegans identified through lethal mutations. J. Cell Biol. 124: 475-490. 


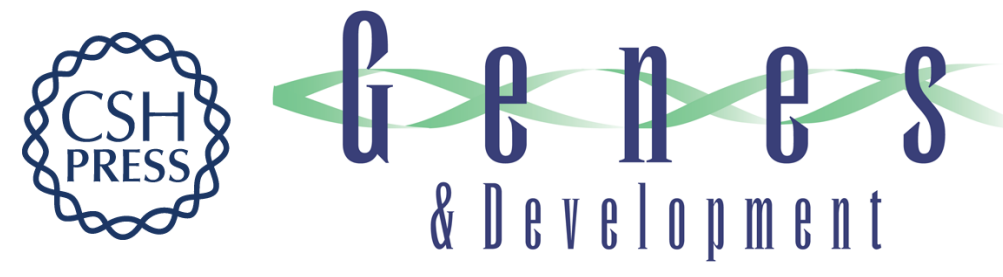

\section{Genetic redundancy masks diverse functions of the tumor suppressor gene PTEN during C. elegans development}

Yo Suzuki and Min Han

Genes Dev. 2006, 20:

Access the most recent version at doi:10.1101/gad.1378906

Supplemental
Material http://genesdev.cshlp.org/content/suppl/2006/02/01/20.4.423.DC1

References This article cites 31 articles, 16 of which can be accessed free at: http://genesdev.cshlp.org/content/20/4/423.full.html\#ref-list-1

License

Email Alerting

Receive free email alerts when new articles cite this article - sign up in the box at the top Service right corner of the article or click here.

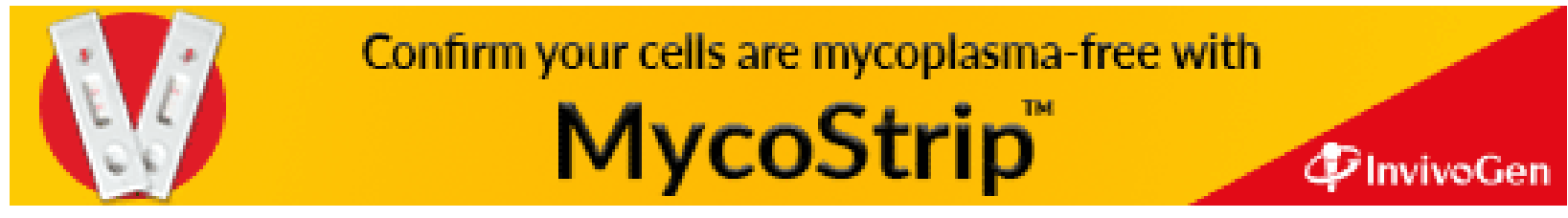

